\title{
Museari, Educar en Arte LGTB para Superar la Homofobia yla Transfobia
}

\author{
Museari, Educate in LGBT Art to Overcome Homophobia and \\ Transphobia
}

\author{
Ricard Huerta * \\ Universitat de València, España
}

\section{DESCRIPTORES:}

Educación

Arte

Museo

Cultura visual

Formación del profesorado LGTB

\section{RESUMEN:}

La presente investigación parte de un proceso de intervención en las aulas de formación del profesorado que pretende generar un acercamiento a las posibilidades educativas del arte LGTB, cuyo objetivo consiste en reflexionar sobre la oportunidad de utilizar piezas artísticas, incorporando cuestiones como la diversidad sexual y de género, fomentando asíla superación del odio, la homofobia y la transfobia. Como metodología se plantea un estudio de caso en el que se analiza un taller impartido a dos grupos de la Facultat de Magisteri de la Universitat de València, incorporando la Investigación Educativa Basada en Artes. La recogida de datos se lleva a cabo durante la práctica docente, usando instrumentos de evaluación como diagnósticos, grupos focales y observación participante, fomentando el debate como fuente de argumentación al tratar cuestiones de diversidad sexual. Como resultado destaca la buena acogida de la temática por parte del alumnado, quienes reconocen haber superado estereotipos y tabús convencionales, propiciando con ello entornos inclusivos, lo cual repercute en la formación de docentes desde el respeto a la diversidad y la educación inclusiva. Como discusión final, expresar la conveniencia de asumir la falta de atención curricular hacia estas cuestiones.

\section{KEYWORDS:}

Education

Art

Museum

Visual culture

Teacher training

LGBT

\section{ABSTRACT:}

This research offers an intervention process in teacher training classrooms, generating an approach to the educational possibilities of LGTB art. The objective is reflecting the opportunity to use pieces of art, incorporating issues such as gender and sexual diversity, promoting the overcoming of hatred, homophobia and transphobia. As a methodology, a case study is presented, analyzing a workshop given to two groups of students at the Faculty of Magisteri of the University of Valencia, also incorporating Arts-Based Educational Research. Data collection is carried out during teaching practice, using assessment instruments such as diagnoses, focus groups and participant observation, fostering debate as a source of argumentation when dealing with issues of sexual diversity. As a result, we highlight the good reception of the subject by the students, who acknowledge having overcome conventional stereotypes and taboos, thereby promoting inclusive environments. All this improves teacher training by increasing respect for diversity and inclusive education. As a final discussion, it is convenient to assume the lack of curricular attention to these issues.

CÓMO CITAR:

Huerta, R. (2021). Museari, educar en arte LGTB para superar la homofobia y la transfobia. Revista Internacional de Educación para la Justicia Social, $10(2), 43-58$.

https://doi.org/10.15366/riejs2021.10.2.003

*Contacto: ricard.huerta@uv.es

ISSN: 2254-3139

revistas.uam.es/riejs
Recibido:

15 de febrero 202

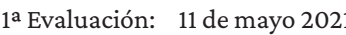

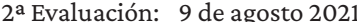

Aceptado: 16 de septiembre 2021 


\section{Introducción}

En las aulas universitarias de formación inicial del profesorado de Educación Primaria detectamos una enorme carencia en lo referido a conocimientos sobre arte o prácticas artísticas. Este déficit se debe a la poca atención que se presta al arte (y al estudio de las imágenes en general) en las sucesivas etapas escolares. Ni el arte ni la diversidad sexual son cuestiones abordadas suficientemente durante la formación escolar. Al no disponer de una preparación adecuada en ambos aspectos, el alumnado llega a la carrera de Magisterio con importantes lagunas, lo cual produce un total desencuentro con las realidades disidentes, y en general con el patrimonio cultural artístico (Panciroli, 2016). Pensamos que es posible superar este desencuentro si somos capaces de generar un ambiente propicio al conocimiento de las artes y las realidades disidentes. Entendemos que son cuestiones importantes para lograr mejorar en aspectos clave como la justicia social o el equilibrio interseccional. Para ello incidimos de modo especial en la formación del profesorado, difundiendo el arte realizado por artistas LGTB entre futuros maestros y maestras. Además de una capacitación teórica, incorporamos talleres de arte y experiencias participativas, mediante las cuales puedan poner en práctica su potencial creativo, sin perder de vista la deriva digital (Álvarez y Cabrera, 2020).

Desde la educación artística propiciamos un conocimiento situado, fomentando la creatividad y la interculturalidad (Said-Valbuena, 2019). Abordamos el reto desde la práctica. Compaginamos las aportaciones teóricas con los talleres, convirtiendo así el aprendizaje en experiencia vivida, impulsando el pensamiento creativo (Sennett, 2013). Estas iniciativas nos deparan resultados altamente positivos. Nuestra investigación plantea la necesidad de incorporar el arte y las creaciones LGTB en la formación del profesorado, con la intención de preparar futuros docentes más respetuosos con la diversidad, en un ambiente educativo inclusivo y exigente (Arriaga y Aguirre, 2020). De este modo atendemos a la reflexión planteada por Nancy Fraser y Judith Butler en relación con las nuevas urgencias sociales y políticas:

Las reivindicaciones del «reconocimiento de la diferencia» estimulan las luchas de grupos que se movilizan bajo la bandera de la nacionalidad, la etnicidad, la «raza», el género y la sexualidad. En estos conflictos «postsocialistas», la identidad de grupo reemplaza al interés de clase como motivo principal de movilización política. La dominación cultural reemplaza a la explotación en tanto injusticia fundamental. Y el reconocimiento cultural reemplaza a la redistribución socioeconómica como remedio contra la injusticia y como objetivo de la lucha política. (Butler y Fraser, 2016, p. 23)

Estudiar el arte hecho por artistas desde el museo online Museari nos permite reflexionar en base a un proceso de trabajo donde se cuestionan los roles tradicionales y los prejuicios de género, potenciando el respeto hacia la diversidad, fomentando subjetividades libres de estereotipos, atendiendo a situaciones tan actuales como los procesos de tránsito en personas trans, o bien situaciones ya conocidas, tan reprobables como el bullying homofóbico hacia el alumnado más indefenso.

\section{Referentes conceptuales}

La cultura visual es un concepto que atiende al imaginario colectivo de una comunidad y que sirve para que esta se identifique (Huerta, 2018). También se entiende como todo el conjunto de imágenes que transmiten discursos diseñados y difundidos por el poder para generar determinadas impresiones en quienes reciben dicha información, expandiendo así una mentalidad en la que perduran unos ideales políticos, o bien sirven para adoctrinar a la ciudadanía. Acercándonos al posicionamiento de Duncum (2008), la cultura visual destaca por la influencia que genera en las personas que la consumen, sin un cuestionamiento de las informaciones que les son impuestas. La influencia es mayor entre quienes se enfrentan a un proceso de descubrimiento del entorno, quienes todavía están en proceso de formación, concretamente aquellas personas que componen el colectivo escolar (Huerta y Alonso-Sanz, 2015). Tal y como nos indican Marcellán y Agirre (2008), refiriéndose al poder de los medios audiovisuales:

El poder de la cultura mediática, especialmente la visual, ha generado en nuestro país una situación de permanente alarma social, que se vive con especial preocupación cuando se tra- 
ta de las relaciones de niños y jóvenes con los medios audiovisuales, especialmente la televisión, y del papel que estos medios están cumpliendo en su formación. (p. 530)

De entre las posibilidades y ejemplos que ofrece la cultura visual, para esta investigación se rescata la cultura de las disidencias sexuales a través de artistas y obras expuestas en el museo online Museari. También revisamos la experiencia titulada "69 disidencias", como ejemplo de práctica colaborativa. Propiciamos el conocimiento de estas realidades a través del arte, mediante un museo online especializado en temáticas LGTB, y a través de acciones reivindicativas. Mediante estos recursos educamos en inclusión, atendiendo a la necesidad de incorporar una alfabetización visual de calidad en las aulas, entendida como aquella que enseña al alumnado a decodificar, analizar, cuestionar y criticar los mensajes que reciben. Se plantea la necesidad de utilizar la imagen y el arte como dispositivos aptos para reflexionar sobre las desigualdades sociales. Gracias a todo ello, el alumnado asimila estos discursos desde una opción inclusiva de respeto hacia la diversidad.

\section{Método}

La presente investigación es eminentemente cualitativa, y parte de una metodología híbrida en la que planteamos un estudio de caso (Stake, 2005), incorporando asimismo la Investigación Educativa Basada en Artes (Rolling, 2017). Nos interesa mejorar la formación del profesorado en materia de cultura visual y diversidad sexual, cuestionando nuestras prácticas docentes y las formas en que generamos conocimiento, nos relacionamos y aprendemos (Pallarès, 2020). Incorporando experiencias y saberes desde la alteridad, valoramos positivamente lo cotidiano, lo diverso, lo que siempre había sido marginado. Impulsamos así la reflexión, la creatividad y la construcción de conocimiento diverso en los entornos de aprendizaje, propiciando así el diálogo con las problemáticas sociales desde la pedagogía crítica, la praxis humanizada y la participación implicada (Arriaga et al., 2018). Esta apertura formativa permite desarrollar un ambiente reflexivo entre quienes habitan los espacios de aprendizaje, para debatir sobre qué elementos de inclusión de la diferencia se han de considerar en las experiencias compartidas (Hernández y Sancho-Gil, 2015). Todo ello nos permite problematizar sobre las prácticas docentes que nos afectan.

Se analiza una experiencia llevada a cabo en las aulas universitarias, donde nos interesa cubrir aspectos de diversidad e inclusión junto con la formación en alfabetización visual (Duncum, 2015), implicando a las personas involucradas en los procesos de enseñanza. También incorporamos la problematización del espacio educativo y sus relaciones de poder, en tanto que reflejo de nuestra sociedad, donde se reproducen situaciones de desigualdad y se discrimina a las disidencias (Sancho-Gil y Hernández, 2018). Nuestra reflexión permite dar visibilidad a la diversidad sexual y de género, de modo que la toma de decisiones en cuanto a qué y cómo abordar el proceso de aprendizaje dependerá del propio contexto (Ramon, 2019).

\section{Diseño de la investigación}

Para diseñar esta investigación, se ha optado por el análisis de dos experiencias: 1) El uso en el aula de un museo virtual con artistas y temáticas LGTB, y 2) Un taller situado titulado "69 disidencias" en el que se exponen al público materiales gráficos diseñados por el alumnado. Como en ambos casos se trata de dos grupos de alumnado de primaria, se ha considerado oportuno establecer el mismo criterio. En la propuesta Museari establecemos un análisis de fuentes y una comparativa de distintos artistas, mediante un estudio de caso, para observar con detenimiento y desde la perspectiva del profesorado en formación qué detecta el alumnado de grado de maestro especialista en primaria respecto a la temática estudiada. La muestra se recoge entre el alumnado de la materia "Propuestas didácticas en educación artística". A partir de una encuesta y de los comentarios que nos ofrece el grupo focal llegamos a una serie de resultados, entre los que destaca la implicación del alumnado, a quienes ha motivado muy especialmente la temática tratada, por la novedad, y por el interés que provoca. Se trata, según las categorías elaboradas por Robert Stake (2005), de un estudio de caso instrumental, ya que se generaliza a partir de una situación específica, examinando el caso para profundizar en un tema, de modo que el caso juega un papel de apoyo para llegar a la formulación de afirmaciones sobre el objeto de estudio. El arte sirve tanto para mostrar como para ocultar ciertas realidades, afectando finalmente a nuestro análisis de los procesos sociales y comunicativos (Briggs y Burke, 2002). Por todo ello, desentrañar los productos mediáticos a través de la cultura 
visual resultará beneficioso para nuestro alumnado, en tanto que futura comunidad docente (Karpati et al., 2017).

Necesitamos una escuela muy impregnada de los saberes y valores de la justicia social, de modo que el profesorado reflexione sobre las necesidades que comporta una verdadera atención a la diversidad, utilizando para ello la cultura visual (Miranda et al., 2017). La escuela es un entorno muy impregnado de visualidad, por lo que estudiar sus esquemas desde la cultura visual permite indagar en cuestiones sociológicas, semióticas y artísticas, fomentando prácticas docentes que suponen un reto constante desde la innovación educativa (Huerta, 2020). Es por ello que reforzamos estas acciones para ofrecer a nuestro alumnado universitario elementos significativos que les ayuden a crecer como docentes. Tenemos en cuenta sus propios intereses, atendiendo a la construcción de narrativas personales. Activamos prácticas artísticas en entornos de mediación pedagógica concibiendo la educación desde un planteamiento crítico (Escaño, 2019). Al revisar y valorar referentes LGTB, elaboramos distintos niveles de problematización para identificar los discursos del poder (Chung, 2007).

\section{Participantes, técnicas de recogida y análisis de la información}

Nuestros proyectos incorporan experiencias artísticas como engranajes de transformación social, descubriendo nuestro entorno para mejorarlo (Sousa, 2018). La lucha contra la discriminación tiene aquí un papel fundamental, ya que proponemos un entorno escolar como lugar de procesos reflexivos y de problematización de las cuestiones sociales (Giroux, 1990), generando debates que afectan al estudiantado de manera directa, como la discriminación por género, la marginación o la desigualdad. De este modo incorporamos problemáticas que permean desde la sociedad, fomentando la utilización de prácticas artísticas (Huerta y Domínguez, 2020), y logrando construir conocimiento artístico (Hamlin y Fusaro, 2018) con un sentido político que va de lo íntimo y personal a lo compartico y común (Alegría et al., 2018). Generamos pensamiento crítico desde la práctica artística para aumentar tanto la creatividad como la libertad en una sociedad transformadora (Huerta, 2019). Elaboramos un modelo de investigación que entiende las prácticas artísticas como agentes articuladores de subjetividades, siempre pendientes de las problemáticas de género y las cuestiones de índole social. Se trata de un enfoque cualitativo con carácter exploratorio (Yin, 2009), por la novedad de temáticas abordadas en este contexto particular.

La metodología de trabajo se ubica en el ejercicio de la docencia universitaria. Participan un total de 100 estudiantes de la mención "Arte y Humanidades". El estudio se hace en una asignatura optativa que cuenta con alumnado interesado por las artes y sus posibilidades educativas (Hernández, 2008). La unidad de análisis es una materia de 3er curso del grado de maestro/a de primaria, con una edad promedio de 22 años y un total de 100 participantes. Se considera esta unidad de análisis por dos razones: 1) El contenido curricular de la asignatura que permite articular el enfoque de inclusión y la disciplina; y 2) El encuentro con la práctica de las artes por parte del alumnado implicado en la investigación. En las clases incorporamos debates, que parten de reflexiones iniciales, de modo que puedan surgir opiniones y respuestas a las problemáticas expuestas, más aún en tiempos de pandemia (Díez Gutiérrez y Gajardo Espinoza, 2020). La dinámica de cada actividad incluye asimismo talleres creativos y participativos, con los que intentamos que el alumnado supere sus prejuicios respecto al arte y sus dinámicas (Santamaría, 2019). El estudio se ha realizado durante el curso 2020-2021, de modo que hemos asumido el esfuerzo de investigar atendiendo a los cambios producidos por la pandemia de la Covid-19 (Montenegro et al., 2020), que en ocasiones nos obligaba a cambiar de formato presencial a virtual (Huerta y Alonso-Sanz, 2020).

Murillo y otros (2017) nos recomiendan que "los datos, como materia prima, han de ser expuestos clara y precisamente como resultados de la investigación” (p. 23). Aquí se ha optado por presentar en el apartado de resultados una selección de las respuestas obtenidas. Los datos se recogieron a través de entrevistas semi-estructuradas, análisis de documentación y observaciones participantes. Sin haber recurrido a un programa, el proceso seguido ha supuesto la lectura de todas las respuestas con el fin de establecer paralelismos en las contestaciones obtenidas, analizando aquellos datos que permiten identificar similitudes en dichas respuestas, contrastándolos y generando estructuras de acceso como criterio de calidad de la investigación cualitativa. La triangulación de datos se establece en el debate entre los especialistas del grupo de investigación. Las técnicas de recolección y construcción de los datos se definen en base a distintos parámetros, a saber: diagnóstico inicial de cada actividad; desarrollo de talleres; organización de grupos focales; diagnóstico final de cada acción realizada. El procedimiento de análisis se establece 
desde la discusión analítica de los datos recogidos en esta investigación de tipo cualitativo. Se establecen categorías de análisis emergentes del diagnóstico inicial, y se lleva a cabo una prospección de los datos desde la construcción de una matriz de doble entrada. Los conocimientos previos del alumnado pueden abrir caminos y opciones integradoras (Alonso-Sanz, 2020), además de resultar muy eficaces para que se sientan realmente partícipes de las acciones (Alves y Pinto, 2019).

\section{Resultados}

Las actividades propuestas que hemos seleccionado para estudiarlas en su proceso y analizar resultados son dos trabajos por proyectos que se ofrecen al alumnado en la materia "Propuestas didácticas en educación artística". En primer lugar, estudiamos el proyecto "Artistas Museari”, con el que acercamos al alumnado universitario de Magisterio al conocimiento de la diversidad sexual, ya que realizan un ejercicio que consiste en elaborar una memoria a partir de una exposición de arte contemporáneo en un museo digital (Rodicio-García et al., 2020). El segundo proyecto es el titulado "69 disidencias", en el cual el alumnado participa en una acción y posteriormente relata su experiencia mediante un cuestionario específico.

El análisis de los datos recogidos nos permite elaborar una indagación sobre aquello que conoce el alumnado universitario respecto a las posibilidades de las artes en su conocimiento de determinadas problemáticas. El papel del arte puede resultar atractivo para el estudiantado al incorporar la diversidad sexual, redescubriendo conceptos como "disidencia", lo cual permite acercarnos a la realidad de colectivos invisibilizados (Ancarola et al., 2017). Abarcamos aspectos de reflexión social (Freire, 2015), percibiendo estructuras de significado conceptual que permite el lenguaje del arte (Barthes, 1986). No podemos permanecer ajenos a las realidades que tanto afectan a las personas que sufren acoso o persecución por su disidencia sexual (Huerta, 2017). La ciudadanía debe atender a las necesidades de las minorías, visibilizando sus problemáticas, consiguiendo así un mayor grado de concienciación frente a los mensajes de odio (Appiah, 2019), apostando por el papel comunicativo y la función social del arte (Benjamin, 2003).

\subsection{Caso 1. Proyecto "Artistas Museari"}

Al iniciar las explicaciones del proyecto "Artistas Museari” presentamos este museo online y la forma de acceder sus más de 70 exposiciones temporales. Se trata de muestras en las que se abordan temáticas vinculadas a los colectivos LGTB. Al hablar a nuestro alumnado de estos artistas a través de sus obras en el museo virtual, les estamos animando a generar recursos educativos para el futuro, puesto que van a ser docentes, y necesitan argumentos para unir arte, diversidad y educación (Greteman, 2017). No perdamos de vista que las futuras maestras y maestros serán quienes compartirán con su alumnado numerosos análisis sobre la cotidianidad (Dewey, 2008). También incorporamos a las clases teóricas referencias a los movimientos de defensa de los derechos humanos para las minorías LGTB, que han dado paso a lo que podríamos denominar una verdadera efervescencia del activismo. Tras estas primeras sesiones formativas pasamos al taller. Buena parte del alumnado considera que "no sabe de arte" o que "nunca se le dio bien el arte". Partir de lo que ya conocen simplifica mucho la tarea. Por ello recurrimos a momentos en los que han tenido experiencias formativas donde se abordasen tema de arte (Saura, 2016). Quisiera incidir en que se trata de futuros maestros y maestras de primaria, estudiantes de grado que solamente cursan una asignatura obligatoria de artes ( 6 créditos) en toda la carrera. Con este ínfimo bagaje inicial se enfrentarán después a su experiencia docente en las aulas.

El taller consiste en elaborar una propuesta didáctica a partir del conocimiento de la obra de artistas que exponen en Museari. Mediante una clase inicial preparatoria y participativa, se imparten una serie de sesiones en las que se explican los temas abordados en las exposiciones que presenta Museari (Saura y Plaza Marcos, 2013). A partir de aquí, cada estudiante realiza su propuesta personal, eligiendo una muestra que le resulte especialmente significativa. En el 21\% de casos coincidieron al elegir la exposición Visibly Intersex de Del LaGrace Volcano (Figura 1), que trata de las personas Intersex. Un 16\% del alumnado eligió la exposición Bustos, de Ángel Pantoja (Figura 2). Para activar el debate, se anima al alumnado a presentar en clase su propuesta y comentarla. Después se da paso una sesión de taller en la que se explican detalladamente los modelos elegidos. 


\section{Figura 1}

Hiker Chiu. Interseex in Taiwan

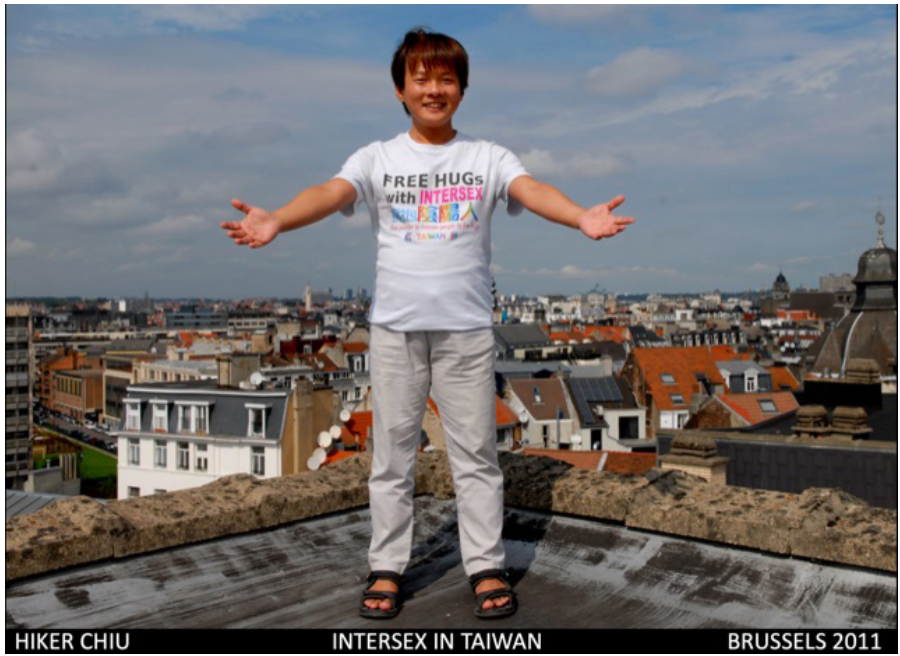

Nota. Del LaGrace Volcano en Museari.

Figura 2

Busto 14

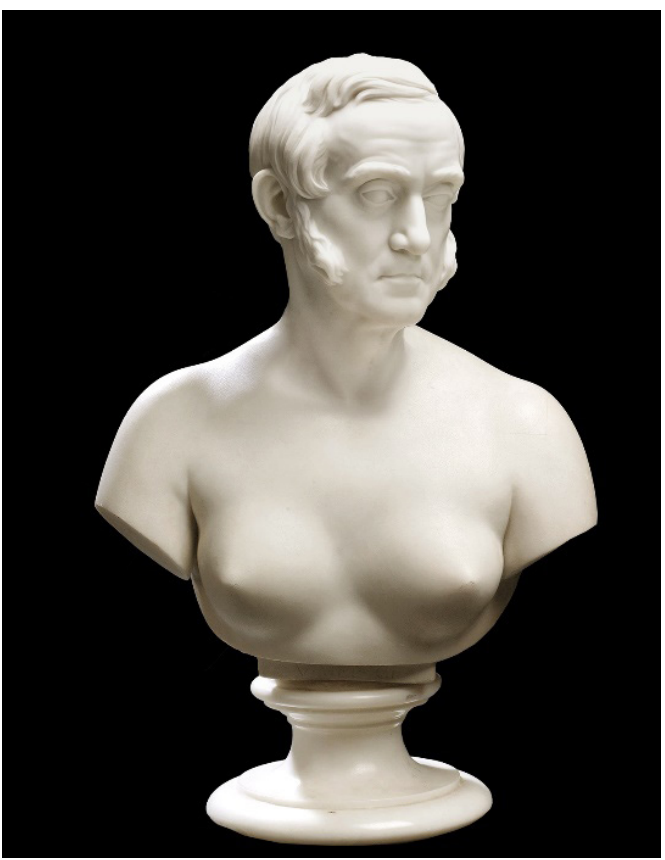

Nota. De la exposición en Museari del artista Ángel Pantoja.

Este ejercicio sirve para que se familiaricen con las diversidades LGTB, generando actividades inclusivas para el aula. Llevamos a cabo un proceso diagnóstico, no solo de la actividad, sino también de las acciones, que contemplan aspectos teóricos y del conocimiento previo que tenía el alumnado al respecto. Se pasa un cuestionario donde se indaga sobre la relación del estudiantado con las diversidades LGTB, haciendo preguntas en torno al conocimiento que tienen de estas cuestiones. A partir del diagnóstico, se organizaron las respuestas desde dos categorías: 1) Conocimiento de las culturas LGTB; y 2) Diseño de actividades artísticas para el aula de Primaria. 
Figura 3

Libertar-se
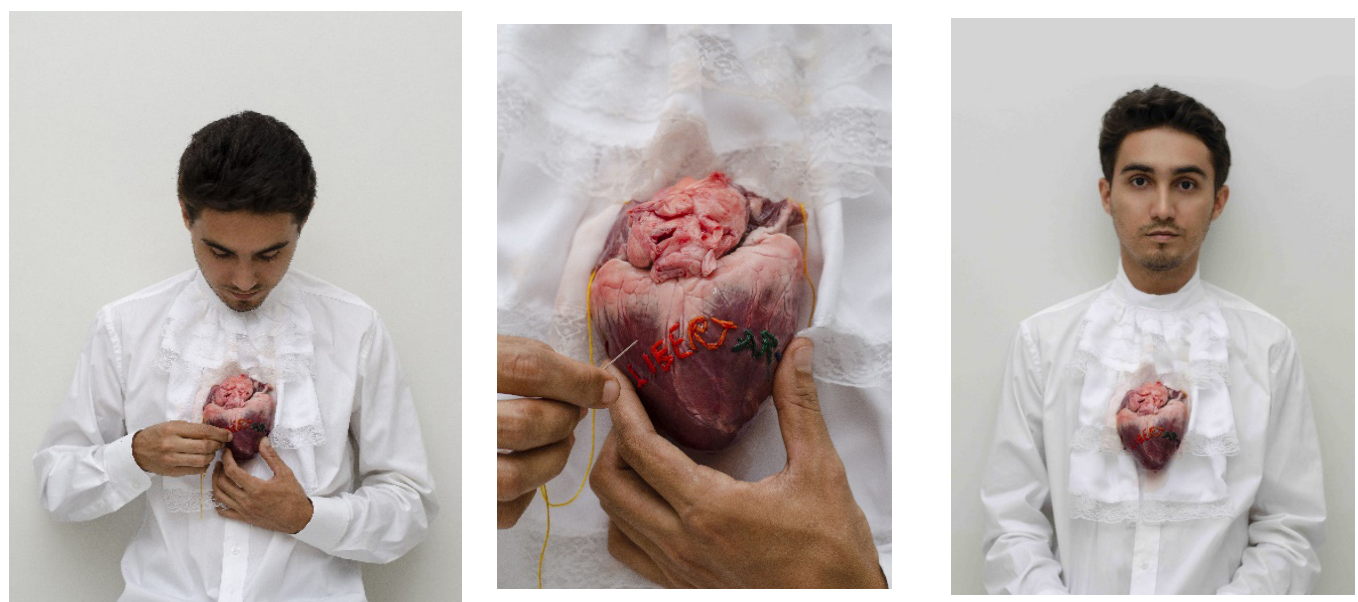

Nota. Recuperado del tríptico del artista brasileño Lucas Villi.

\subsubsection{Categoría "Conocimiento de las culturas LGTB"}

El alumnado plantea una falta de conocimiento de estas realidades, a pesar de considerarlas muy interesantes. Entre las respuestas más recurrentes del diagnóstico se encuentra el desconocimiento de esta realidad desde la perspectiva de lo visual, y los prejuicios adquiridos respecto estos temas. Leemos frases que se repiten con frecuencia en el diagnóstico con relación a la pregunta ¿Te habías planteado antes la importancia delas imágenes en las culturas LGTB? A lo que responden, en función de la muestra elegida:

Se ha investigado poco sobre las experiencias de los estudiantes intersex en la escuela, y muy pocos docentes sabrían cómo hacer para que se sientan seguros, comprendidos e incluidos. (Estudiante 19)

El tema intersex es un reto para acercarse a la igualdad real en la escuela. El asunto merece toda nuestra atención. (Estudiante 65)

Si bien esta serie de bustos de Ángel Pantoja puede sacar una sonrisa al espectador, hay que escarbar un poco más en la obra y ver el mensaje que nos envía. (Estudiante 80)

Evidenciamos que antes no se habían planteado las diversidades desde la creación artística, ni tampoco las culturas LGTB como un escenario visual. La gran mayoría (89\%) confirma haber descubierto nuevas motivaciones, y se ha sentido atraída con el ejercicio del taller. En este sentido, la actividad supone un verdadero desafío, ya que incorpora reflexión, identidad, conocimientos, inclusión y justicia social, y se traslada la discusión hacia las posibilidades que habitan en el campo de la visualidad (García-Huidobro y Schenffeldt, 2020).

Figura 4

La Virgen de Copacabana a la que bailan las trans de Cusco

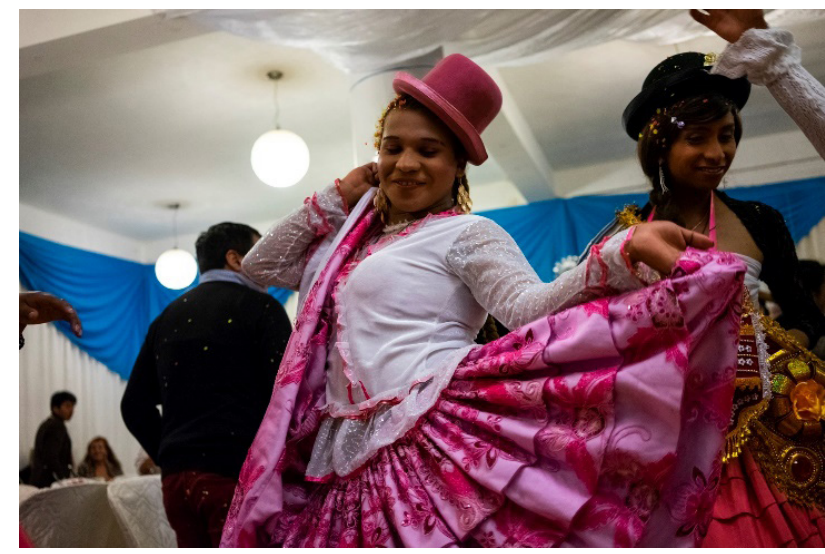

Nota. Pieza de Eva Máñez en su exposición de Museari. 


\subsubsection{Categoría "Diseño de actividades artísticas para el aula de Primaria"}

Esta categoría genera dudas al alumnado, poco habituado a plantearse soluciones artísticas, ya que en su formación nunca hubo demasiada atención hacia las artes visuales, por eso se encuentran poco familiarizados con el potencial visual de estos recursos. La reflexión les ayuda a superar estos desencuentros:

Debemos adoptar un lenguaje inclusivo, evitando términos despectivos o anticuados como "hermafrodita", eliminando el lenguaje dañino, como hablar de niños y niñas "normales". (Estudiante 9)

Me ha tocado muy de cerca la exposición de Lucas Villi, porque en mi familia hay una persona abiertamente homosexual, algo que todavía acarrea consecuencias negativas, porque en nuestra sociedad hay un sector muy necio que no lo acepta. (Estudiante 33)

La fiesta da lugar al respeto y acercamiento entre colectivos. ¿Pero qué ocurre cuando se acaba la fiesta? Volvemos al principio, a la indiferencia por estas personas trans. (Estudiante 89)

A partir de los relatos incorporados a este diagnóstico, se elaboran las actividades, poniendo en el centro del proceso analítico y crítico las ideas de cada participante, que tendrá que desarrollar su propia propuesta. La actividad responde a cuestiones relevantes como la defensa de los derechos humanos o el respeto hacia las personas que rompen esquemas convencionales. Al identificar esos aspectos llevamos a cabo un proceso de identificación de estereotipos que forman parte de la vida cotidiana del alumnado (Figura 3). Se problematiza a partir de sus propias experiencias, actitudes y formas de mostrarse al mundo (Figura 4). El taller permite que el alumnado identifique elementos visuales como la composición o el uso de luz, colores y texturas, o los contrastes simbólicos. Tras la presentación de los trabajos, se abre un debate para definir qué aspectos han resultado más interesantes o motivadores, y para comprobar cómo podríamos aplicar lo aprendido a las clases de primaria, que es donde trabajarán en el futuro (Bourriaud, 2009). Tanto el proceso llevado a cabo como los resultados permiten evaluar críticamente los trabajos realizados, que son propuestas de corte artístico, implicadas y situadas, que transmiten sentimientos y problemáticas. Sirve también para explicar en clase el uso de diferentes materiales y procedimientos con propósitos expresivos (Errázuriz Larraín y Fermandois-Schmutzer, 2021).

\subsection{Caso 2. Proyecto "69 Disidencias"}

Animamos al alumnado a participar en esta iniciativa que forma parte del proyecto I+D "Sensibilización en igualdad de género y diversidad sexual mediante intervenciones artísticas en contextos universitarios". Les invitamos a generar carteles reivindicativos en hojas de papel de $50 \times 70 \mathrm{~cm}$. Posteriormente, con estas hojas intervenidas se elabora una gran "S" (la inicial de la palabra "Sensibilización"). Al hacer las pinturas, se sorprenden de los resultados, tanto a nivel de contenidos como desde una perspectiva gráfica. Las creaciones combinan textos e imágenes, que sirven para denunciar la violencia de género y el acoso hacia personas LGTB.

Figura 5

Una inmensa "S" de "Sensibilización" ocupa el hall de la Facultat de Magisteri

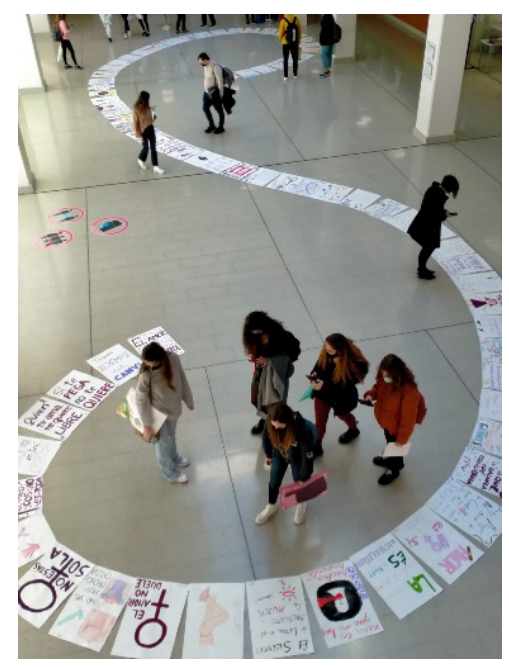


Un factor que resulta sugerente para el alumnado universitario es la posibilidad de ocupar un espacio transitado de la facultad como entorno que se convierte en soporte de sus propuestas creativas (Figura 5). Incorporamos las acciones colaborativas para llevar a cabo a nuestra acción pedagógica, adecuándola así a la formación de docentes. Artistas importantes como Jenny Holzer o Barbara Kruger utilizan los textos en sus obras, mediante composiciones que hablan de violencia, sexualidad, poder, guerra, desde el feminismo, consiguiendo una posición ética desde un discurso que une tecnología, política, religión y filosofía (Penna Tosso et al., 2020). Al revisar la obra de estas artistas somos conscientes del poder visual de los textos.

Figura 6

Estudiantes observando un fragmento de la gran letra "S" formada por 69 composiciones gráficas

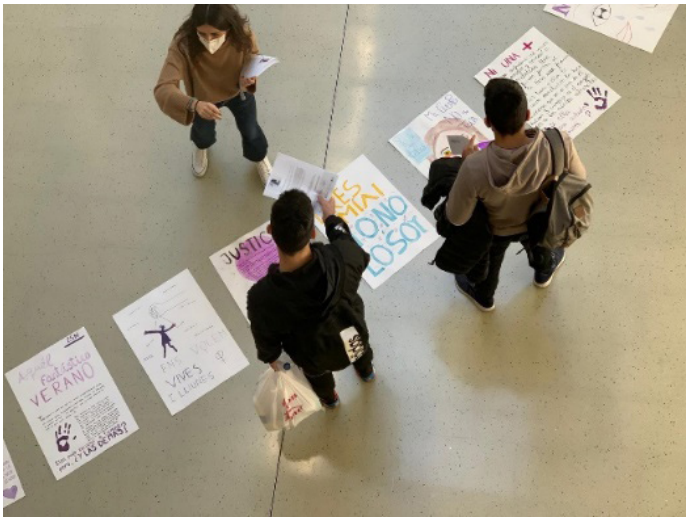

Al igual que hicimos en el primer caso, se realiza un diagnóstico para conocer los niveles de conocimiento del alumnado respecto a las representaciones vinculadas a la lucha contra la violencia de género o el bullying homofóbico y transfóbico (Figura 7). Se les anima a construir significados, evidenciando la violencia simbólica en sus entornos cotidianos, buscando especialmente los significados en los elementos visuales (Mirzoeff, 2006). De este modo se establece un debate sobre el papel de las reivindicaciones LGTB, analizando los materiales con los que se realizan estas acciones, las estéticas que transmiten, así como la capacidad comunicativa que conllevan. El diagnóstico nos llevó a comprobar que más del 71\% del alumnado pudo establecer un criterio de adecuación entre las acciones realizadas y su adecuación técnica. Todo esto permite un mayor conocimiento de las realidades LGTB. Algunas ideas que emergen en el diagnóstico atienden a estos elementos:

He tenido la suerte de no presenciar ningún acto de violencia en mi vida, pero creo que es imprescindible que esto acabe ya. (Estudiante 8)

Me parece una acción necesaria para concienciar a la población de los problemas reales que sufrimos las mujeres y los colectivos LGTB. (Estudiante 41)

Me ha gustado ver los carteles y me han hecho pensar y accionar. (Estudiante 77)

Al preguntar por el concepto de diversidad, las respuestas son menos precisas, pero incorporan igualmente elementos de reflexión:

Pienso que es un tema realmente importante, que hay que tratar, y que tiene mucha relación con la educación recibida. (Estudiante 3)

Las personas trans están ahí y los espacios que ocupan y deben ocupar son los mismos que los de cualquier otra persona. (Estudiante 18)

Vivimos en una sociedad totalmente binaria en la que todavía se hace hincapié en la dualidad de roles que deben adoptar hombres y mujeres. (Estudiante 36)

La bandera del orgullo representa mucho más que la pertenencia a un colectivo, es uno de los símbolos más fuertes para hacerse visible. (Estudiante 54) 
Figura 7

Profesorado y alumnado participan en esta acción de sensibilización que utiliza el arte como estrategia educativa de justicia social

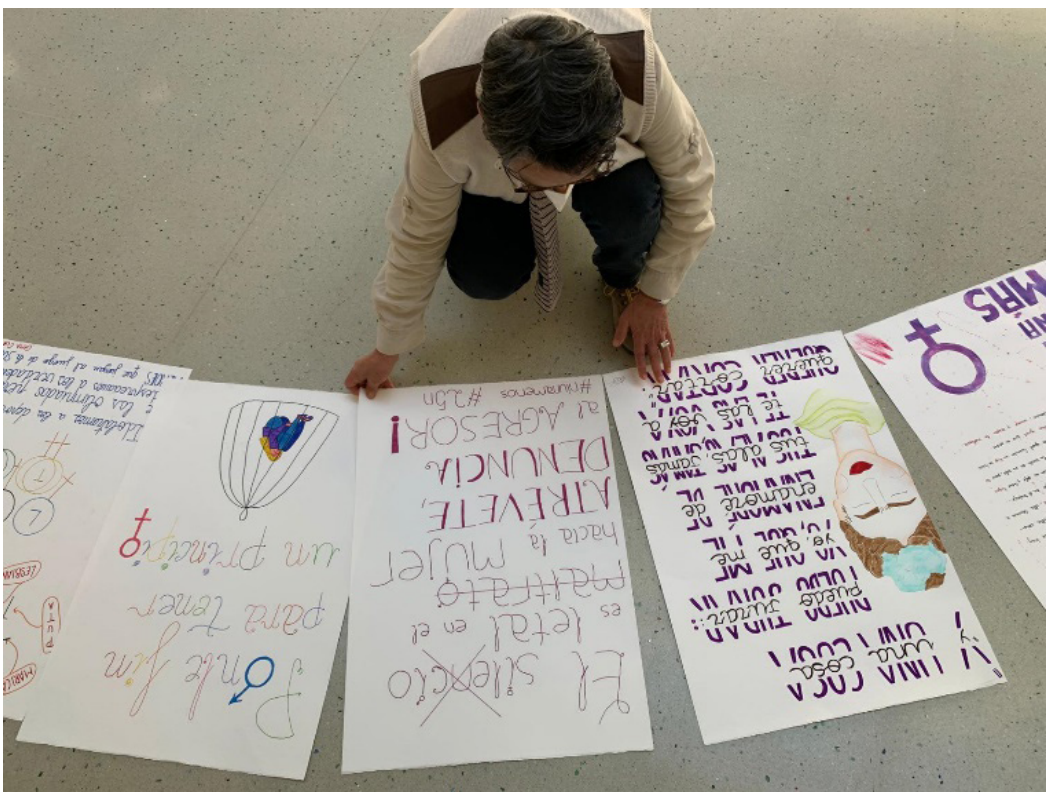

Cuestionamos el imaginario colectivo sobre el género para desarrollar un ejercicio deconstructivo sobre los significados sociales de las imágenes, presentes en el discurso escolar (Figura 7). En la dimensión metodológica intentamos vincular los contenidos con experiencias personales, constatando el relato del alumnado respecto a las cosas y formas de representar que son "para niños o niñas", cuestionando estas divisiones o roles. Al terminar la actividad, las reflexiones del estudiantado apuntan al cuestionamiento del deber social, a la libertad de expresión y a la necesidad de construir escenarios educativos más libres de estereotipos.

\section{Discusión}

Las encuestas se entregan a 100 estudiantes del Grado en Maestro/a en Educación Primaria en la Facultat de Magisteri de la Universitat de València, siendo un total del 100\% quienes responden. Como datos demográficos de la muestra a destacar que tenemos un $72 \%$ de participantes mujeres frente al $28 \%$ de encuestados hombres. La mayoría (88\%) tiene edades comprendidas entre 20 y 30 años. Utilizamos lenguajes artísticos para ir más allá de la mera representación, lo cual repercute en las formas de conocer y valorar, cuestionando los procesos tradicionales de enseñanza y aprendizaje (Eisner, 2004). La investigación indaga en las posibilidades de transformar los entornos cotidianos, eliminando prejuicios y tabúes respecto a la diversidad sexual y los roles de género, haciendo uso de las imágenes desde el artivismo (Huerta, 2021). Desarrollamos procesos expresivos y reflexivos. Las dos actividades estudiadas como casos estimulan al alumnado a repensar sus dinámicas sociales y a la necesidad de desmarcarse de situaciones de violencia de género, homofobia y transfobia. Estas actividades fomentan un profesorado más colaborativo y respetuoso, utilizando la actividad artística para mejorar las situaciones de desigualdad. Los dos casos presentados abordan problemáticas actuales de tipo personal y social desde la investigación artística. Rescatamos pequeñas historias, cuestionando los grandes relatos, configurando identidades y compartiendo subjetividades colectivas. Fomentamos experiencias artísticas donde surgen elementos personales que permiten adentrarnos en las realidades colectivas, avanzando así hacia una educación más inclusiva y desarrollando procesos creativos y reflexivos. Les animamos a generar fotografías a partir de las experiencias realizadas (Pérez y Bedoya, 2019) 
Figura 8

Mediante una intervención artística, el hall de la Facultat de Magisteri se convierte en un espacio reivindicativo de corte social

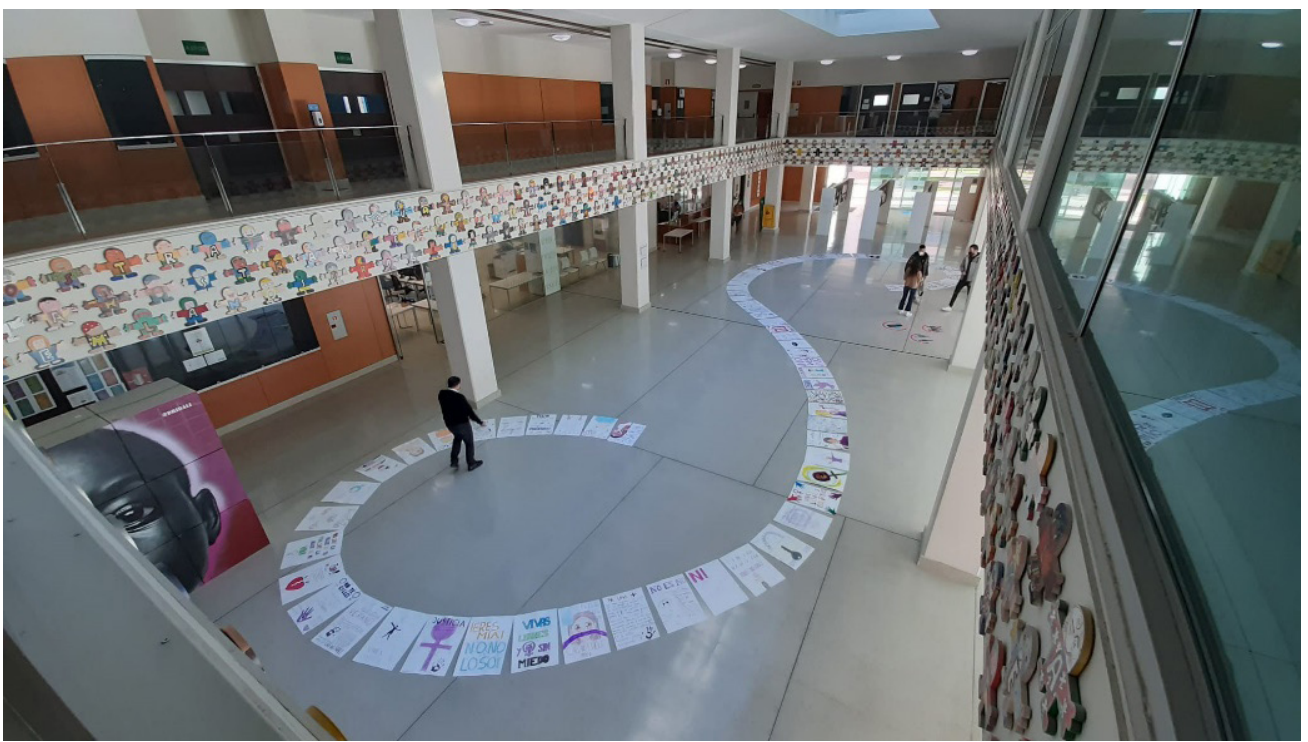

Nota. Foto realizada por David Mascarell.

Tras la discusión de resultados, resulta necesario comentar los hallazgos en base a la relación entre la muestra encuestada y el propio concepto. El 83\% de participantes afirma interesarse y preocuparse por las cuestiones LGTB. No obstante, pese a dicha preocupación generalizada, tan solo en 6 casos confirman haber participado en iniciativas, acciones protesta o actividades solidarias a favor de personas LGTB. Si bien una parte del alumnado no participa de modo habitual en actividades como las propuestas presentadas, muestran intención de hacerlo en el futuro. Así se manifiesta una preocupación social entre la mayoría de estudiantes del Grado en Maestro en Educación Primaria (Méndez, 2016).

Profundizando más en la cuestión, al preguntar “¿Qué importancia le das al tratamiento de las cuestiones LGTB en educación?” el $48 \%$ de la muestra lo considera un tema muy importante, el $43 \%$ importante y tan solo una minoría restante del $9 \%$ como regular. Observamos hallazgos similares en relación con la pregunta "¿Qué importancia consideras que tiene el arte para incorporar cuestiones LGTB en las aulas?" ya que una mayoría de $53 \%$ considera importante dicho aspecto, un $42 \%$ muy importante y tan solo el $5 \%$ lo considera regular. A la pregunta “¿Piensas que es importante abordar el tema LGTB e forma transversal en Educación Primaria?” todas las respuestas son positivas. También consideran preciso que la alfabetización visual se efectúe desde los primeros años de escolarización. Todo ello apunta hacia una mayor preocupación por la presencia de la educación artística en las aulas.

Preguntas más específicas como: “¿Crees que en la problemática de las cuestiones LGTB, el hecho de ser hombre o mujer puede suponer una diferencia sustancial?" o “¿Consideras que el tratamiento de las realidades LGTB puede mejorar aspectos educativos en Primaria?", nos aportan datos significativos de lo que piensa esta generación de estudiantes al respecto. Una mayoría defiende el sí para las desigualdades de género, por la estructura social heteropatriarcal que todavía perdura y dificulta el empoderamiento de la mujer como colectivo (Butler, 2006). Una minoría (23\%) no es consciente de esta desigualdad en términos de género, ni tampoco detecta de la existencia de micromachismos sociales. En relación con la población LGTBIQ todas las respuestas son afirmativas, y consideran a este colectivo susceptible se tener dificultades en el ámbito social. Se considera oportuno introducir todas estas temáticas en las aulas, incorporando cuestiones de arte y cultura visual. La mirada normativa que elimina sistemáticamente las otredades puede resultar muy perjudicial para numerosas personas que resultan afectadas por durísimos procesos de discriminación, violencia o invisibilidad (Zafra, 2017).

Las encuestas también nos demuestran que existe un gran interés por parte del alumnado hacia problemáticas como la violencia contra las personas trans o el bullying hacia los niños y niñas que no encajan en los márgenes convencionales de sexo y género. A pesar de su concienciación social y política, comproba- 
mos que no habían detectado hasta qué punto tanto los medios de comunicación como el propio currículum escolar nunca abordan estas cuestiones, desviando así la atención hacia problemáticas y urgencias de gran calado. Tras analizar los resultados obtenidos, constatamos que hace falta una mayor formación sobre realidades LGTB entre el futuro profesorado, con el fin de formar a maestros y maestras conscientes del poder educativo que puede adquirir un currículum escolar libre de tabús (Foucault, 2009).

\section{Conclusiones}

La presente investigación nos revela aspectos importantes sobre el tratamiento de las cuestiones de diversidad LGTB en la formación del profesorado de Primaria. Hemos incidido en el tratamiento de la cuestión desde la educación artística, y llegamos a la conclusión de que dicha temática sigue siendo prácticamente inexistente en el currículum escolar, al igual que ocurre en la formación del profesorado. Anular estas realidades, invisibilizarlas o desdeñarlas supone también eliminar del ámbito educativo un problema que afecta a millones de personas. Al no exponer la problemática, se genera una invisibilidad maniquea hacia dicha cuestión. Esto afecta finalmente al conjunto del profesorado y el alumnado, entre quienes también, evidentemente, población LGTB. Son los miedos y los prejuicios, así como una tradición obstinadamente homofóbica, las causas de la ocultación de estas realidades, lo cual perjudica a la hora de establecer cualquier posibilidad de mirada crítica desde el trabajo pedagógico.

El estudio se ha ubicado también en el paradigma de la cultura visual, acotando en este caso los márgenes de análisis a las posibilidades de formación en las distintas etapas educativas. Mediante un estudio de caso centrado en un grupo de docentes en formación, comprobamos hasta qué punto estas temáticas siguen ausentes de la realidad educativa. Las encuestas al alumnado universitario revelan que, si bien conocen aspectos puntuales de estas realidades diversas, no pueden identificar claramente cada situación específica, por lo que resulta complejo que su visión de la diversidad LGTB pueda basarse en una reflexión meditada de lo que representan las disidencias sexuales.

Generar un acercamiento a la defensa de los derechos humanos y el respeto a la diversidad mediante el estudio de las imágenes de las disidencias LGTB se puede llevar a cabo incorporando la visualidad a nuestros recursos educativos, considerando los objetos culturales y artísticos elaborados por los movimientos disidentes, así como sus modalidades de creación, presentación, consumo o recepción crítica. Esto significa que no se trataría de objetos autónomos, sino de herramientas que nos permitan comprender la organización de las sociedades contemporáneas y las relaciones sociales de poder que las estructuran, siguiendo los pasos de los estudios culturales. Se trata de no ver en estos artefactos visuales representaciones simbólicas culturales y simples de las políticas en funcionamiento en las comunidades LGTB, sino también para subrayar su capacidad de producir y fortalecer identidades colectivas, o renegociar sus significados. El uso de un museo online como Museari propicia estos acercamientos, involucrando a la tecnología digital. También las acciones colaborativas, como la actividad "69 Disidencias”, permiten al alumnado y profesorado hablar abiertamente de estas cuestiones de sexo y género. La identidad no debe entenderse como algo fijo y esencialista, como una unidad naturalmente estable e inalterada, sino como un concepto estratégico y situado que surge del juego de modalidades específicas de poder. En este sentido, activistas, docentes y artistas pueden unirse en torno a una identidad colectiva, cristalizando diferentes demandas. La identidad también es una cuestión de estética, que sirve para elaborar una amplia reflexión sobre las realidades culturales LGTB y sus dimensiones políticas. La afirmación de esta sensibilidad constituye una identidad artística y cultural específica, empoderándose de todo un panorama visual para superar la marginación. Estas prácticas, que también deben ser consideradas como estrategias militantes, dan fe del lugar único del individuo en las movilizaciones, que siempre tienen una vertiente artística, explorando nuevas perspectivas en la historia de las representaciones de corporalidades marginales o marginadas. Su conocimiento y difusión ayudan a una mejor comprensión de los problemas y las modalidades de la dinámica subjetiva y afectiva en la articulación de corpus iconográficos y teóricos, así como en la construcción de representaciones.

Al elaborar un discurso pedagógico para al futuro profesorado de Primaria, incidiendo en los Derechos Humanos y el respeto al colectivo LGTB, planteamos la necesidad de mejorar su labor docente, ya que desde un mayor acercamiento a las imágenes que durante décadas ha generado el mundo LGTB, el alumnado percibe mejor las posibilidades creativas de las disidencias. Al mismo tiempo actualizamos el lenguaje y 
los recursos de las artes visuales, pensando en las necesidades escolares actuales, muy impregnadas por el papel predominante de la imagen, así como por los usos de la tecnología digital. Intentamos acercar el universo LGTB al alumnado universitario, desde una perspectiva múltiple, atendiendo a cuestiones estéticas, culturales, éticas y de implicación social. Con esto conseguimos que buena parte del alumnado supere los prejuicios que tiene hacia la práctica de las artes, convirtiendo el estudio y la creación LGTB en potenciales creativos de todo el alumnado. Teniendo en cuenta los resultados obtenidos, la intención es seguir incorporando temáticas que abracen las urgencias sociales en nuestras clases de artes, investigando así el modo como favorecen una mayor implicación social y mejor conocimiento de las problemáticas sociales entre futuros docentes.

\section{Agradecimientos}

Este trabajo se inscribe en el proyecto I+D+i "Sensibilización en igualdad de género y diversidad sexual mediante intervenciones artísticas en contextos universitarios" con financiación de la Generalitat Valenciana GVA a través de la Conselleria de Innovación, Universidades, Ciencia y Sociedad Digital (Referencia: GV/2020/069).

\section{Referencias}

Alonso-Sanz, A. (2020). Una profesora "flâneuse" en París. Cartografías en la formación inicial de docentes. Arte, Individuo y Sociedad, 32(2), 363-386. https://doi.org/10.5209/aris.63670

Álvarez, A. y Cabrera, J. F. (2020). Requerimientos para el diseño de la experiencia de inmersión en laboratorios virtuales. Revista KEPES, 17(22), 277-299. https://doi.org/10.17151/kepes.2020.17.22.11

Alves, L. A. y Pinto, H. (2019). Educación histórica con el patrimonio: Desafiando la formación del profesorado. Revista Electrónica Interuniversitaria de Formación del Profesorado, 22(1), 71-81. https://doi.org/10.6018/reifop.22.1.356381

Ancarola, N., Manonelles, L. y Gasol, D. (2017). Politizaciones del malestar. Derecho a la angustia. El arte y los procesos creativos como instrumento para canalizar el malestar. RaigVerd.

Appiah, K. A. (2019). Las mentiras que nos unen. Repensar la identidad. Taurus.

Arriaga, A. y Aguirre, I. (2020). Colaboración museo-universidad para renovar la mediación en arte y patrimonio histórico. El caso del Museo de Navarra. Arte, Individuo y Sociedad, 32(4), 989-1008. https://doi.org/10.5209/aris.66295

Arriaga, A., Marcellán, I. y Aberasturi-Apraiz, E. (2018). Mediación crítica en arte y cultura visual. Pulso. Revista de Investigación, 41, 13-17.

Barthes, R. (1986). Lo obvio y lo obtuso. Imágenes, gestos, voces. Paidós.

Benjamin, W. (2003). La obra de arte en la época de su reproductibilidad técnica. Ítaca.

Bourriaud, N. (2009). The radicant. Lukas \& Sternberg.

Briggs, A. y Burke, P. (2002). De Gutenberg a internet. Una historia social de los medios de comunicación. Taurus.

Butler, J. (2006). Deshacer el género. Paidós.

Butler, J. y Fraser, N. (2016). ¿Redistribución o reconocimiento? Un debate entre marxismo y feminismo. Traficantes de sueños.

Chung, S. K. (2007). Media literacy art education: Deconstructing lesbian and gay stereotypes in the dedia. International Journal of Art and Design Education, 26(1), 98-107. https://doi.org/10.1111/j.1476-8070.2007.00514.x

Díez Gutiérrez, E. J. y Gajardo Espinoza, K. (2020). Políticas educativas en tiempos de coronavirus: La confrontación ideológica en España. Revista Internacional de Educación para la Justicia Social, 9(3), 83-101.

https://doi.org/10.15366/riejs2020.9.3.005 
Duncum, P. (2008). Holding aesthetics and ideology in tension. Studies in Art Education, 49(2), 122-135. https://doi.org/10.1080/00393541.2008.11518730

Duncum, P. (2015). Transforming art education into visual culture education through rhizomatic structures. Anadolu Journal of Educational Sciences International, 5(3), 47-64. https://doi.org/10.18039/ajesi.66849

Eisner, E. W. (2004). El arte y la creación de la mente: El papel de las artes visuales en la transformación de la conciencia. Paidós.

Errázuriz Larraín, L. y Fermandois-Schmutzer, J. (2021). Formación docente para la educación artística en Chile. El desafío cultural pendiente en las escuelas primarias. Arte, Individuo y Sociedad, 33(1), 49-69. https://doi.org/10.5209/aris.67126

Escaño, C. (2019). La mirada como acto político. El cine y otros audiovisuales como herramientas educativas de (re) construcción del mundo. EARI Educación Artística. Revista de Investigación, 10, 251-261. https://doi.org/10.7203/eari.1014152

Foucault, M. (2009). Vigilary castigar. Nacimiento de la prisión. Siglo XXI Editores.

Freire, P. (2015). Pedagogía da autonomía: Saberes necessários à prática educativa. Paz e Terra.

García-Huidobro, R. y Schenffeldt, N. (2020). Subjetividades del profesorado de artes y su rol como agentes/as de cambio. Revista Internacional de Educación para la Justicia Social, 9(2), 173-195. https://doi.org/10.15366/riejs2020.9.2.009

Giroux, H. (1990). Los profesores como intelectuales. Hacia una pedagogía crítica del aprendizaje. Paidós.

Greteman, A. J. (2017). Helping kids turn out queer: Queer theory in art education. Studies in Art Education: A Journal of Issues and Research, 58(3), 195-205. https://doi.org/10.1080/00393541.2017.1331089

Hamlin, J. y Fusaro, J. (2018). Contemporary strategies for creative and critical teaching in the 21st century. Art Education, 71(2), 8-15. https://doi.org/10.1080/00043125.2018.1414529

Hernández, F. (2008). La investigación basada en las artes. Propuestas para repensar la investigación en educación. Educatio Siglo XXI, 26, 85-118

Hernández, F. y Sancho-Gil, J. M. (2015). A learning process within an education research group: An approach to learning qualitative research methods. International Journal of Social Research Methodology, 18(6), 651-667. https://doi.org/10.1080/13645579.2015.1049468

Huerta, R. (2017). Transeducar. Arte, docencia y derechos lgtb. Egales.

Huerta, R. (2018). Miradas urbanas del profesorado iberoamericano desde la cultura visual. Magis, 10(21), 55-76. https://doi.org/10.11144/Javeriana.m10-21.mup

Huerta, R. (2019). Arte para primaria. UOC.

Huerta, R. (2020). Arte, género y diseño en educación digital. Tirant lo Blanch.

Huerta, R. (2021). La imagen como experiencia. McGraw-Hill.

Huerta, R. y Alonso-Sanz, A. (2015). Educación artística y diversidad sexual. PUV.

Huerta, R. y Alonso-Sanz, A. (2020). Humanidades digitales y pedagogías culturales. Saberes virales para una nueva educación. UOC.

Huerta, R. y Domínguez, R. (2020). Por una muerte digna para la educación artística. EARI Educación Artística. Revista de Investigación, 11, 9-24. https://doi.org/10.7203/eari.11.19114

Karpati, A., Freedman, K., Castro, J. C., Kallio-Tavin, M. y Heijnen, E. (2017). Collaboration in visual culture learning communities: Towards a synergy of individual and collective creative practice. International Journal of Art and Design Education, 36(2), 164-175. https://doi.org/10.1111/jade.12099

Marcellán, I. y Aguirre, I. (2008). El valor educativo de los medios: correlaciones socioculturales. Comunicar, 31, 529 535. https://doi.org/10.3916/c31-2008-03-046 
Méndez, P. (2016). Constitución de sujeto maestro en prácticas de resistencia en Colombia. Enunciación, 21(1), 15-30. https://doi.org/10.14483/udistrital.jour.enunc.2016.1.a01

Miranda, F., Vicci, G. y Ardanche, M. (2017). Educación y visualidad. Investigaciones pedagógicas en contextos hiper-visuales. Udelar.

Mirzoeff, N. (2006). On visuality. Journal of Visual Culture, 5(1), 53-79. https://doi.org/10.1177/1470412906062285

Montenegro, S., Raya, E. y Navaridas, F. (2020). Percepciones docentes sobre los efectos de la brecha digital en la educación básica durante el Covid-19. Revista Internacional de Educación para la Justicia Social, 9(3e), 317-333. https://doi.org/10.15366/riejs2020.9.3.017

Murillo, F. J., Martínez-Garrido, C. y Belavi, G. (2017). Sugerencias para escribir un buen artículo científico en educación. REICE Revista Iberoamericana sobre Calidad, Eficacia y Cambio en Educación, 15(3), 5-34. https://doi.org/10.15366/reice2017.15.3.001

Pallarès, M. (2020). Educación humanizada. Una aproximación a partir del legado de Heinrich Rombach. Estudios Sobre Educación, 38, 9-27. https://doi.org/10.15581/004.38.9-27

Panciroli, C. (2016). Los bienes culturales como patrimonio educativo. EARI Educación Artística. Revista de Investigación, 7, 86-99. https://doi.org/10.7203/eari.7.8158

Penna Tosso, M., Sánchez Sáinz, M. y Mateos Casado, C. (2020). Desigualdades educativas derivadas del Covid-19 desde una perspectiva feminista. Análisis de los discursos de profesionales de la educación madrileña. Revista Internacional de Educación para la Justicia Social, 9(3), 157-180. https://doi.org/10.15366/riejs2020.9.3.009

Pérez, J. A. y Bedoya, C. M. (2019). La fotografía como herramienta para el desarrollo de la creatividad y la alfabetidad visual: investigación en el aula. Revista KEPES, 16(20), 377-404. https://doi.org/10.17151/kepes.2019.16.20.14

Ramon, R. (2019). Prácticas artísticas de visualización entre cuerpo y objeto en entornos de mediación pedagógica. Arte, Individuo y Sociedad, 31(13), 509-526. https://doi.org/10.5209/aris.60881

Rodicio-García, M. L., Ríos-de-Deus, M. P., Mosquera-González, M. J. y Penado Abilleira, M. (2020). La brecha digital en estudiantes españoles ante la crisis de la Covid-19. Revista Internacional de Educación para la Justicia Social, 9(3), 103-125. https://doi.org/10.15366/riejs2020.9.3.006

Rolling, J. H. (2017). Arts-based research in education. En Leavy, P. (Ed.), Handbook of arts-based research (pp. 493 510). Guilford.

Said-Valbuena, W. (2019). Prefigurar, co-crear, entretejer. Diseño, creatividad, interculturalidad. Arte, Individuo y Sociedad 31(1), 111-129. https://doi.org/10.5209/ARIS.59369

Sancho-Gil, J. M. y Hernández, F. (2018). La profesión docente en la era del exceso de información y la falta de sentido. Revista de Educación a Distancia, 56, art. 4. https://doi.org/10.6018/red/56/4

Santamaría, A. (2019). Alta cultura descafeinada. Situacionismo low costy otras escenas del arte en el cambio de siglo. Siglo XXI.

Saura, A. y Plaza Marcos, R. (2013). E@: Uso de internet como espacio artístico habitable. Educación Artística. Revista de Investigación, 4, 289-300.

Saura, A. (2016). Proyecto “Un arte realmente útil”. Opción, 32(8), 800-827.

Sennett, R. (2013). El artesano. Anagrama.

Sousa, F. (2018). Inovação no ensino por projeto: Um estudo de caso de resolução criativa de problemas. Revista Internacional de Educación para la Justicia Social, 7(2), 61-76. https://doi.org/10.15366/riejs2018.7.2.004

Stake, R. E. (2005). Investigación con estudio de casos. Morata.

Yin, R. K. (2009). Case study research. Sage.

Zafra, R. (2017). El entusiasmo. Precariedad y trabajo creativo en la era digital. Anagrama. 


\section{Breve CV del autor}

\section{Ricard Huerta}

Catedrático de Educación Artística en la Universitat de València. Artista y docente, es investigador del Instituto de Creatividad e Innovaciones Educativas. Director de "EARI Educación Artística. Revista de Investigación” (www.revistaeari.org). Director del Diploma de Especialización en Educación Artística y Gestión de Museos. Director de Museari (www.museari.com) Fundador de AVALEM Asociación Valenciana de Educadores de Museos y Patrimonios. Coordinador del Grupo CREARI de Investigación en Pedagogías Culturales (GIUV2013-103) (http://www.uv.es/creari). Profesor del Departamento de Didáctica de la Expresión Musical, Plástica y Corporal de la Facultat de Magisteri. Dirige el Proyecto de Innovación Educativa Second Round, Arte y lucha en Secundaria. Miembro del Seminario de Género y Diversidad Sexual de los Museos de Catalunya. Email: ricard.huerta@uv.es

ORCID ID: https://orcid.org/0000-0002-1430-3198 